\title{
CHARACTERIZATION OF LOW-DENSITY POLYETHYLENE WASTE FILLED WITH PALM KERNEL SHELL
}

\author{
F. Inegbedion ${ }^{* 1}{ }^{\boxplus}$, L. C. Igbonazobi ${ }^{2}$, A. O. Imasuen ${ }^{2}$, C. O. Inetianbor ${ }^{2}$ \\ *1, 2 Department of Polymer Technology, Auchi Polytechnic, Auchi. Edo State, Nigeria
}

DOI: https://doi.org/10.29121/ijetmr.v8.i4.2021.918

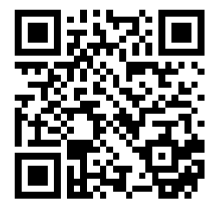

Article Citation: Li-Wei Lin, and

Huei-Ping Chen. (2021).

CHARACTERIZATION OF LOW

DENSITY POLYETHYLENE WASTE

FILLED WITH PALM KERNEL

SHELL. International Journal of

Engineering Technologies and

Management Research, 8(4), 71-78.

https://doi.org/10.29121/ijetmr.v8

.i4.2021.918

Published Date: 28 April 2021

Keywords:

Low Density Polyethylene

Palm Kernel Shell

Composite

Waste

Tensile Strength

Hardness

\section{ABSTRACT}

All over the world, polyethylene wastes has been found littered on the streets of most communities and states. Palm kernel shell (agricultural waste) constitutes dirt and environmental pollution. The aim of this research was to study the potentials of palm kernel shell (PKS) filler as reinforcement for low density polyethylene (LDPE) waste. LDPE-Palm kernel shell composites of varying ratio (100:0, 90:10, 80:20, 70:30, 60:40, 50:50) of LDPE to PKS respectively were produced using the compression moulding technique. Mechanical properties such as water absorption, hardness, young's modulus and tensile strength of the composites were found to increase with increasing PKS loading. The results showed that composites containing $40 \%$ of PKS gave the highest tensile strength corresponding to $18.42 \mathrm{MPa}$. The results also indicated that the composites with $50 \%$ filler loading gave the highest hardness of $84.25 \mathrm{~A}$ and water absorption rate which stood at 3.1\%. The elongation at break was found to decrease with increasing filler content. The scanning electron micrograph (SEM) obtained revealed that the composites with $20 \%$ and $50 \%$ palm kernel shell had voids and surface cracks.

\section{INTRODUCTION}

Growing environmental awareness has resulted in renewed interest in the use of natural materials for different applications considering the serious environmental problems caused by the growing consumption of synthetic polymers. Considerable attention to the natural fibers has picked up momentum both in the literature and in the industry in recent years. Advantages of natural fibers over conventional reinforcement such as glass or carbon fibers are of lower cost, low density, low biodegradability as well as high specific properties (AI-Kaabi et al., 2005). Natural organic fibers from renewable natural resources often have potential to act as biodegradable reinforcing material alternative for the use of glass or carbon fiber and inorganic fillers (Bledzki et al., 1999).

Low density polyethylene (LDPE) is an important thermoplastic because of having a good combination of properties such as fluidity, flexibility, transparency and glossy surface. LDPE is used as food packaging material, sheet and film (Wypych, 2003). In general the utilization of lignocelluloses materials in the production of plastic composites is becoming more attractive, particularly for low cost and high volume applications. Lignocellulosesderived filler possess several advantages compared to inorganic fillers that is; lower density, greater deformability, less abrasiveness to equipment and lower cost. More importantly, lignocellulosic-based filler are derived from renewable resources, available in relative abundance; the potential of which has not been really tapped. Intrinsically, 
these fillers have a number of interesting mechanical and physical properties. Palm kernel shell (PKS) is one of the lignocellulosics bio fibers derived from palm kernel waste (Averous et al., 2005).

The wide use of plastic products in various applications has greatly increased due to their unique properties which include good mechanical properties, resistance to chemical attack and corrosion, ease of processing and recycling, cost effectiveness, light weight and others. However, these properties are affected by many factors such as stress, temperature and environment when they are exposed to service life. An attempt to overcome these obstacles led to incorporation of fillers (inorganic and organic) into plastics composites whose constituents act synergistically to withstand the challenges thereby, making plastics more reliable during use or processing. A composite is a material made from two or more constituent material with significantly different physical or chemical properties that when combined produce a material with characteristics different from the individual components. A composite contain a matrix material and reinforcing material (Josmin, 2012). Generally, the composites properties are influenced by many factors such as filler characteristics, filler content and interfacial adhesion and dispersion due to combination of more than one material (Danyadi et al., 2009).

A lot of research has been carried out in the area of composite development. The use of palm kernel shell based material for brake pad, some in automobile application and many on suitability of some natural filler reinforced composite materials have been studied (Salmah et al., 2012). Palm kernel shell is being used as thermal insulators, previous findings also reported the use of PKS to improve the impact strength of homogenous epoxy (Barkar et al., 2007), and the use of PKS in the production of safety helmet (Akindapo et al., 2017).

Polymer material waste is considered one of the most onerous wastes, constituting an enormous threat to the natural environment. For this reason, recycling of polymer materials is currently one of the most important waste management problems (Vasguez et al., 2016). Polyethylene wastes are usually found littered on the streets of most communities in Nigeria, they constitute environmental pollution, and they are not biodegradable and when gathered and burnt can cause air pollution. Polyethylene wastes accumulates and affect the aesthetic features of our land topography by giving it an unkempt appearance as well as parading habitation for different organisms that can have harmful effect both on their immediate and remote environment.

Palm kernel shells also constitute environmental pollution around the country and also serve as an eyesore. It is clear that these two waste materials are problems to the environment. Hence an attempt was made to convert these materials to useful products by making them into a composite.

\section{MATERIALS AND METHOD}

\subsection{SAMPLE PREPARATION}

Granules of low density polyethylene waste were obtained from Onitsha, Anambra State, Nigeria. The palm kernel shell was collected from Warri metropolis and environs in Delta State, Nigeria. The samples were washed to remove dirt, sun dried for two days to remove excess moisture, grinded and sieved to $90 \mu \mathrm{m}$ particle size.

\subsection{COMPOUNDING OF POLYMER COMPOSITES}

The composites were prepared by compression moulding technique. The LDPE was heated and melted at $180^{\circ} \mathrm{C}$. The mixing of the filler particles with the molten polymer was carried out at a temperature of $180^{\circ} \mathrm{C}$ and pressure of $40 \mathrm{~kg} / \mathrm{cm}^{2}$ for 10 minutes. The procedure was repeated for various amounts of filler reinforcement composites with varying mix ratios of $(100: 0,90: 10,80: 20,70: 30,60: 40,50: 50)$ of low density polyethylene waste and palm kernel shell.

\subsection{X-RAY DIFFRACTION (XRD) CHARACTERIZATION}

The XRD characterization was carried out using X-Ray diffractometer type PW 1800, Model: Rigaku D/Max-IIIC. CuKa radiation $\left(\mathrm{ka}=1.556 \mathrm{~A}^{\circ}\right)$, using a generator tension of $50 \mathrm{kv}$ and current of $20 \mathrm{~mA}$. The diffraction angle was scanned from $10^{\circ}$ to $80^{\circ} 2 \theta$, at a step size of $0.020^{\circ}$ and a rate of 0.250 s. 


\subsection{MECHANICAL PROPERTIES OF COMPOSITES}

Tensile strength, young's modulus and elongation at break were determined using the universal testing machine (UTM) in accordance with ASTM D638. Hardness test was carried out according to ASTM D2240. Water absorption test was carried out according to ASTM D471. Finally, a scanning electron microscope, JEOL JSM-7600F was used for surface characterization of the composites.

\section{RESULTS AND DISCUSSION}

\subsection{X-RAY DIFFRACTION (XRD) RESULTS}

$\begin{array}{lllll}\text { Sample } & : \text { Palm Kernel } & \text { File : Sg2 1.ASC } & \text { Date : July } 18 \text { 8:38:12 } & \text { Operator: } \\ \text { Comment } & : \text { Qualitative } & \text { Memo } & & \\ \text { Method } & : \text { 2nd differential } & \text { Typica width : } 0.065 \text { deg. } & \text { Min. Height } & 240: 00 \mathrm{cps}\end{array}$

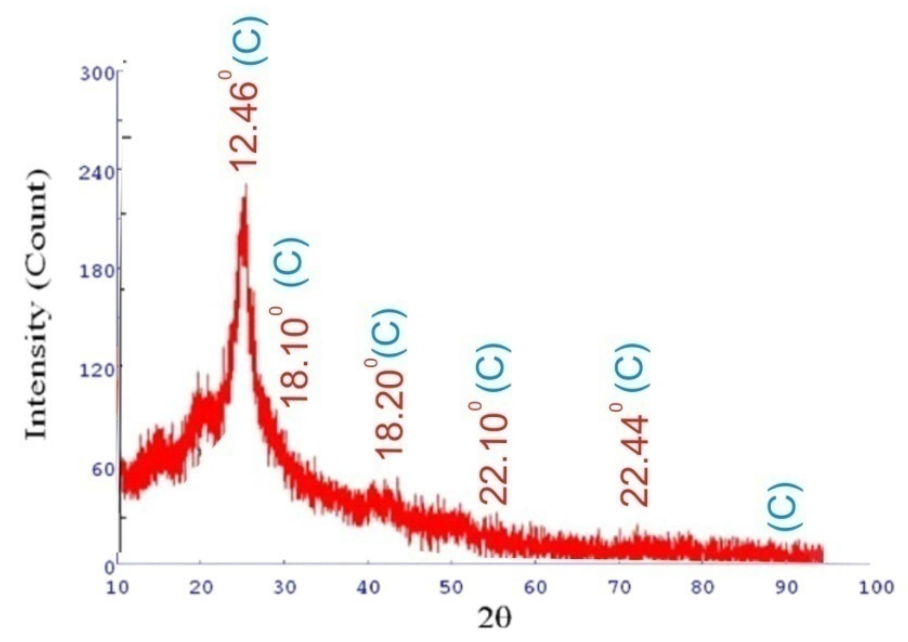

Figure 1: XRD diffraction spectral for palm kernel shell

The XRD spectral obtained is shown in figure 1. There is a broadening and reduction in intensity of the PKS reflections with increasing particles concentration, indicative of altered amorphous and crystalline phases. The result shows a characteristic sharp peak at $2 \theta=25.5^{\circ}$ and indicate the plane of the PKS. A study conducted by (Pendolino et al., 2015) also showed similar diffraction peak.

\subsection{SEM ANALYSIS}

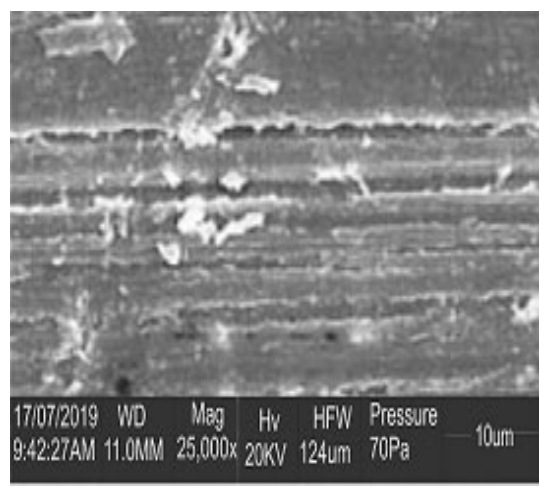

a.

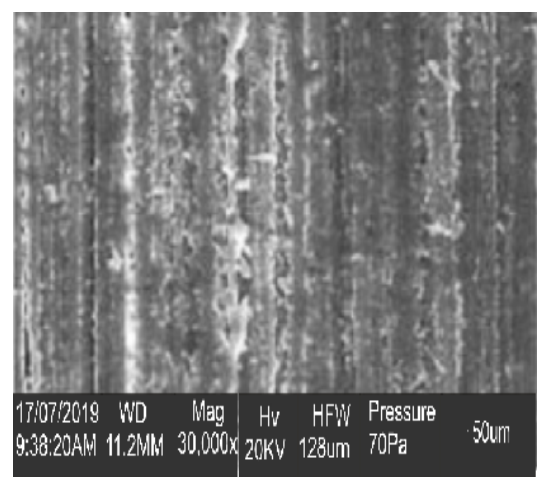

b. 


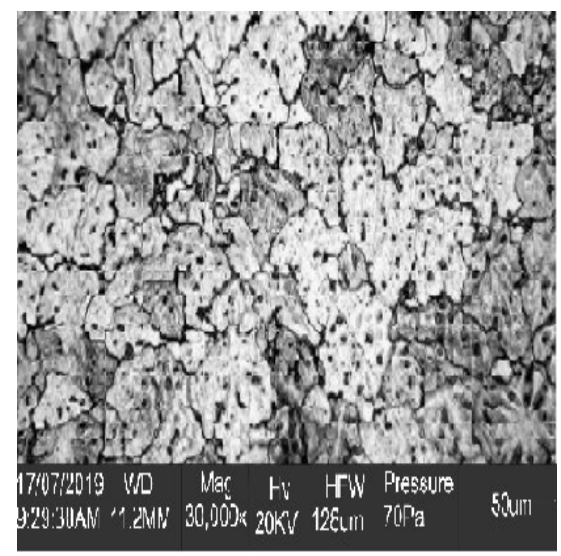

C.

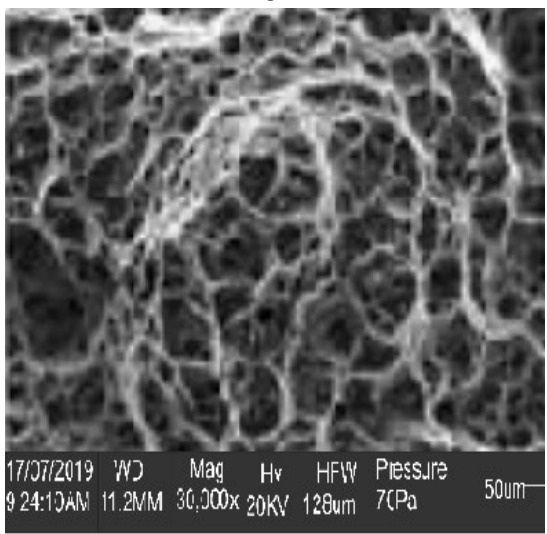

e.

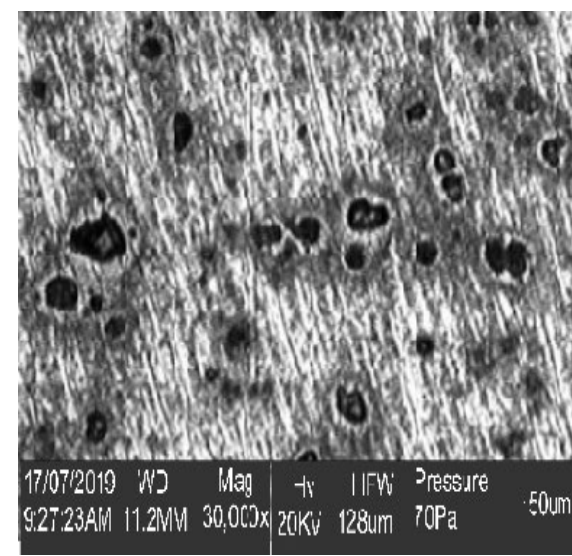

d.

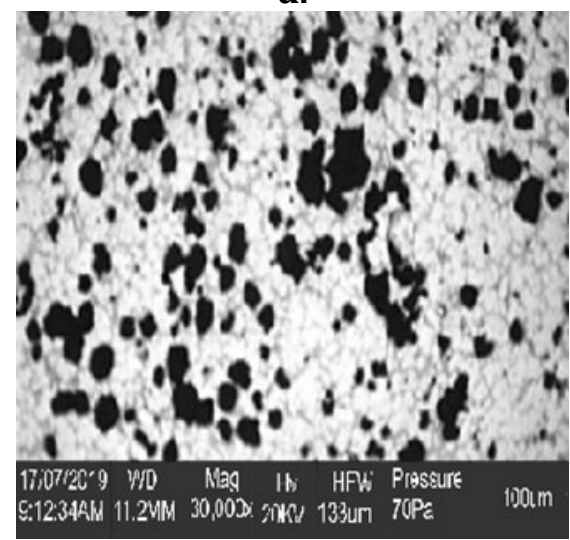

f.

Figure 2: SEM micrographs of composites ratios (a) 100:00 (b) 90:10 (c) 80:20 (d) 70:30 (e) 60:40 (f) 50:50

Figure 2 shows micrographs of composite surfaces using SEM. Particles are wetted by the polymer and the analysis clearly showed differences in microstructure of the composites produced by varying the PKS content.

The micrographs showed void, smooth, fracture features and irregular small flakes on the surfaces. The microstructure revealed a reasonably uniform distribution of PKS in the LDPE matrix.

\subsection{MECHANICAL PROPERTY TESTS}

Table 1: Mechanical property test results

\begin{tabular}{|c|c|c|c|c|c|c|}
\hline & $\begin{array}{c}\text { Samples } \\
\text { LDPE:PKS }\end{array}$ & $\begin{array}{c}\text { Tensile } \\
\text { Strength } \\
(\mathrm{MPa})\end{array}$ & $\begin{array}{c}\text { Hardness } \\
\text { (Shore A) }\end{array}$ & $\begin{array}{c}\text { Water } \\
\text { Absorption } \\
(\%)\end{array}$ & $\begin{array}{c}\text { Elongation at } \\
\text { Break } \\
(\%)\end{array}$ & $\begin{array}{c}\text { Young's } \\
\text { Modulus } \\
(\mathrm{MPa})\end{array}$ \\
\hline Sample A & $100: 00$ & 8.50 & 63.75 & 0.00 & 11.83 & 92.87 \\
\hline Sample B & $90: 10$ & 17.37 & 72.03 & 0.20 & 26.33 & 120.59 \\
\hline Sample C & $80: 20$ & 11.98 & 72.12 & 1.30 & 14.00 & 236.33 \\
\hline $\begin{array}{c}\text { Sample } \\
\text { D }\end{array}$ & $70: 30$ & 16.62 & 73.25 & 2.10 & 7.16 & 301.96 \\
\hline Sample E & $60: 40$ & 18.42 & 74.00 & 2.40 & 10.33 & 340.07 \\
\hline Sample F & $50: 50$ & 11.80 & 84.25 & 3.10 & 7.50 & 387.99 \\
\hline
\end{tabular}




\section{Tensile Strength}

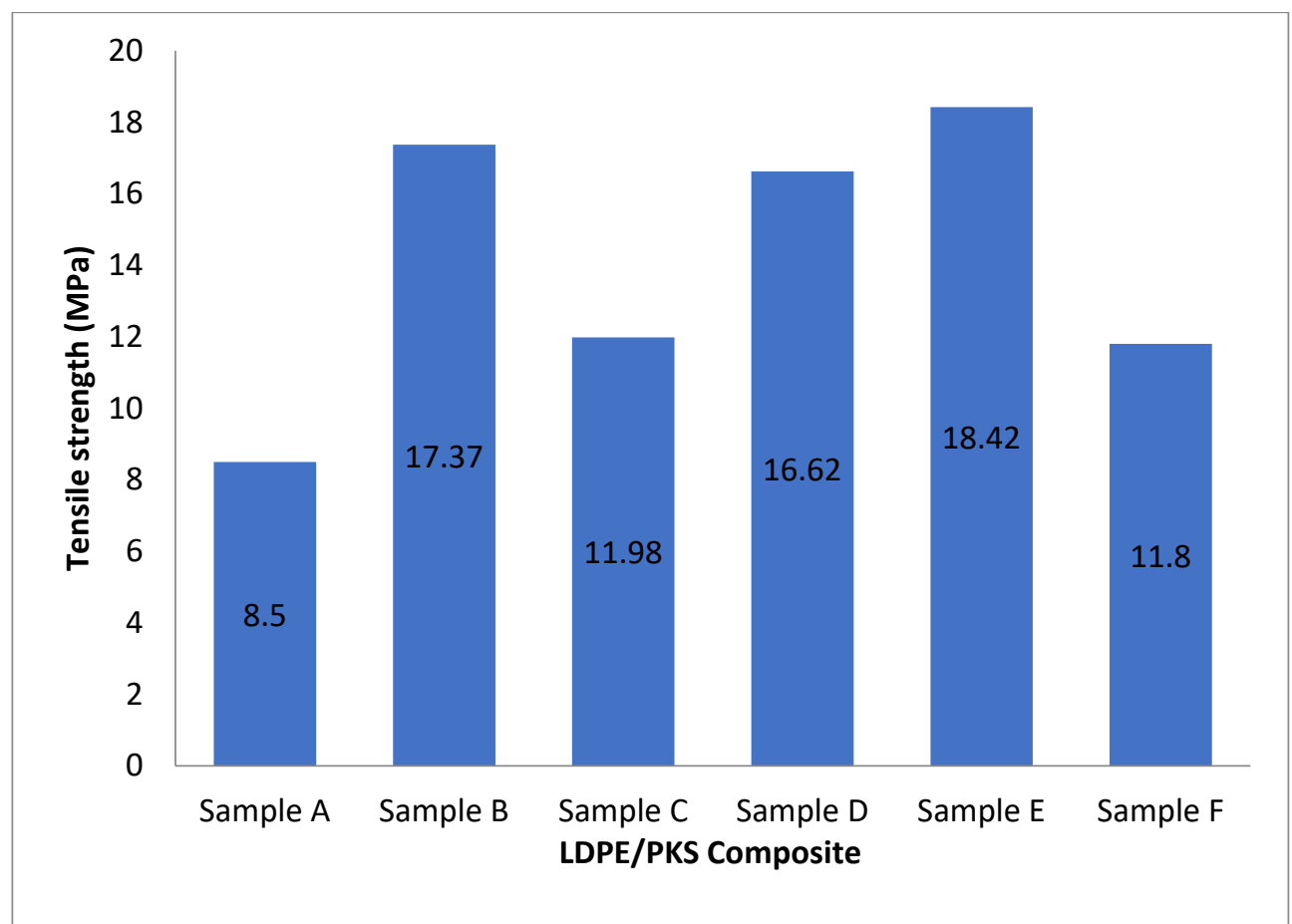

Figure 3: Tensile strength

\section{Hardness}

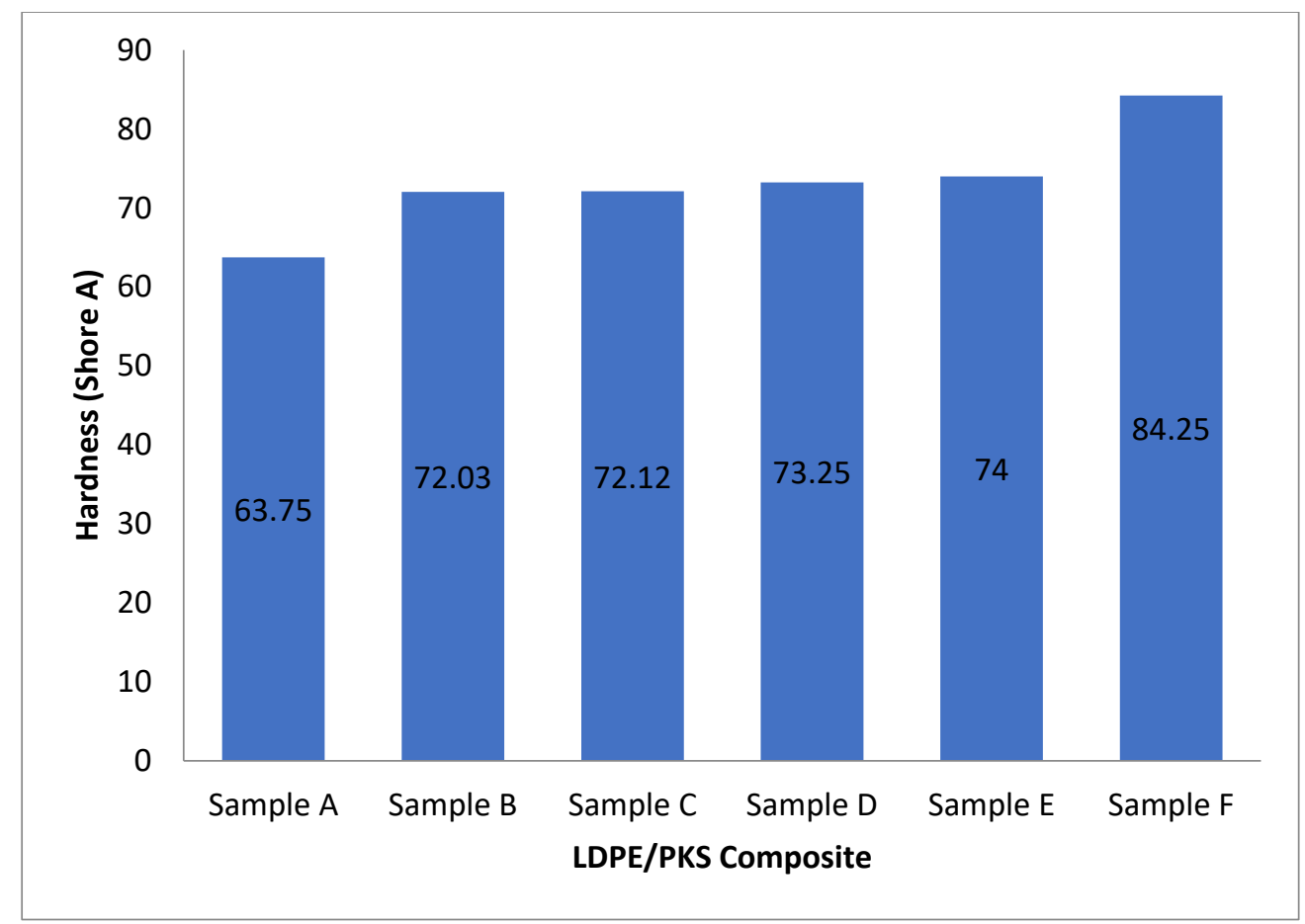

Figure 4: Hardness 


\section{Water Absorption}

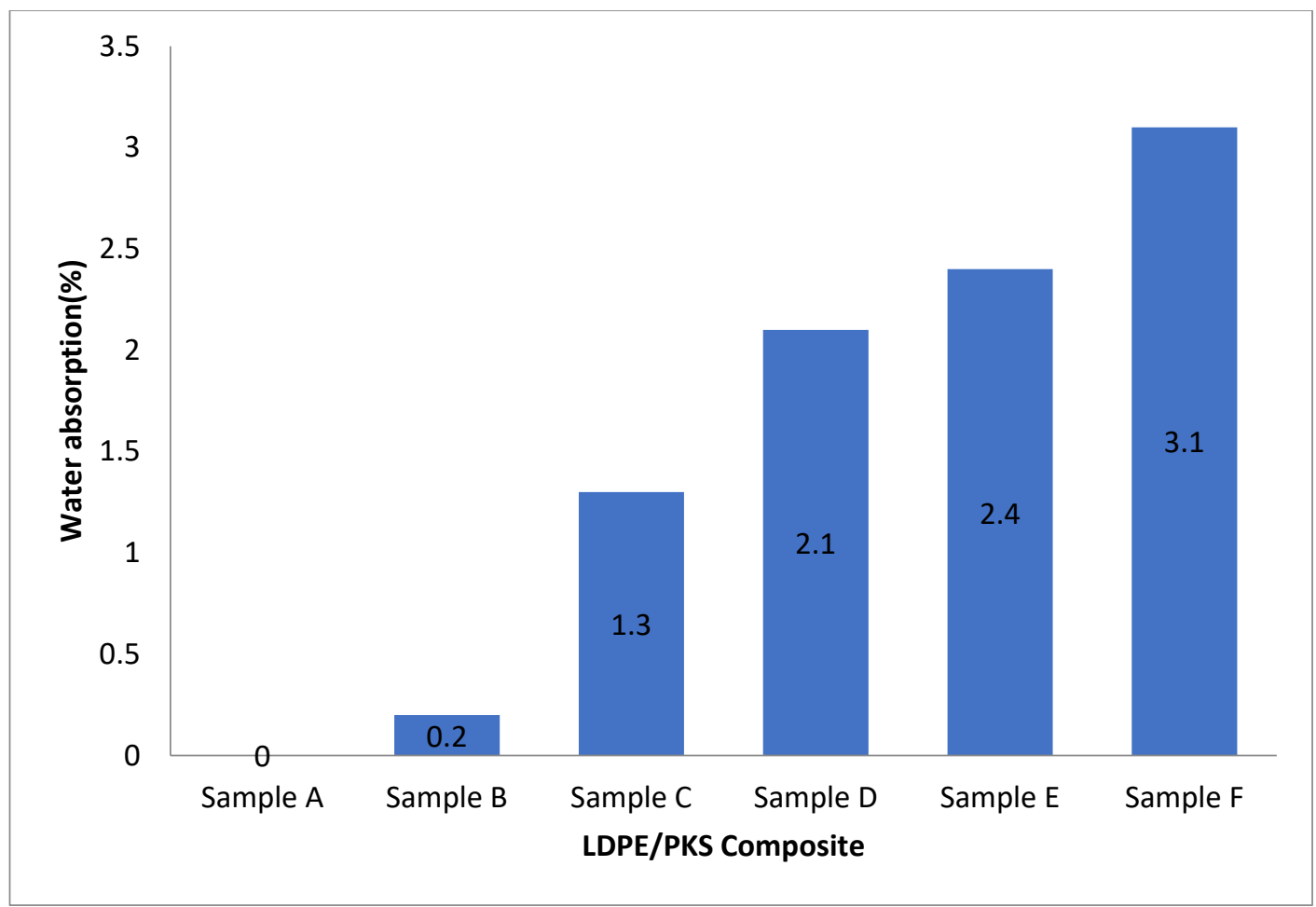

Figure 5: Water absorption

\section{Elongation at Break}

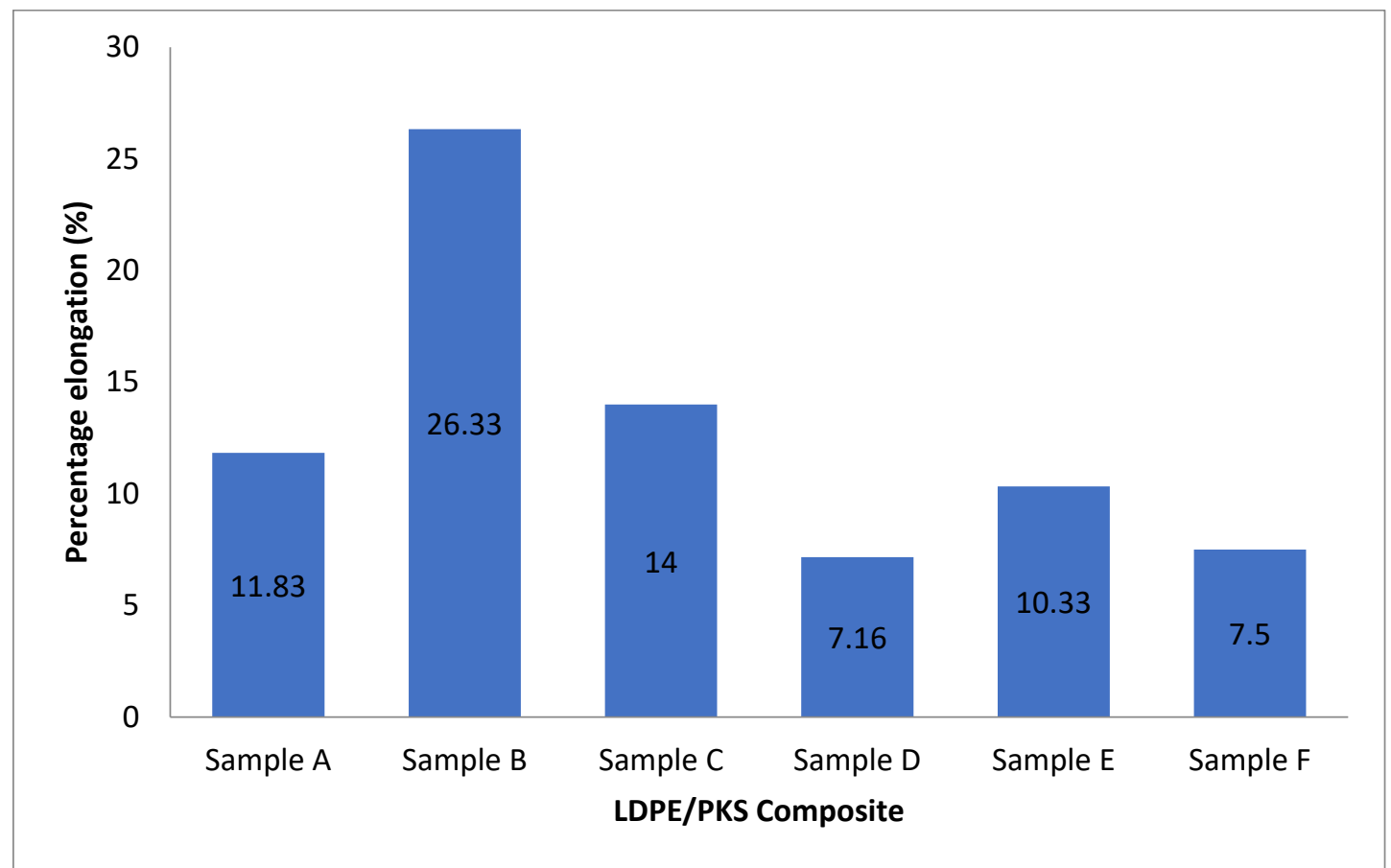

Figure 6: Percentage Elongation 


\section{Young's Modulus}

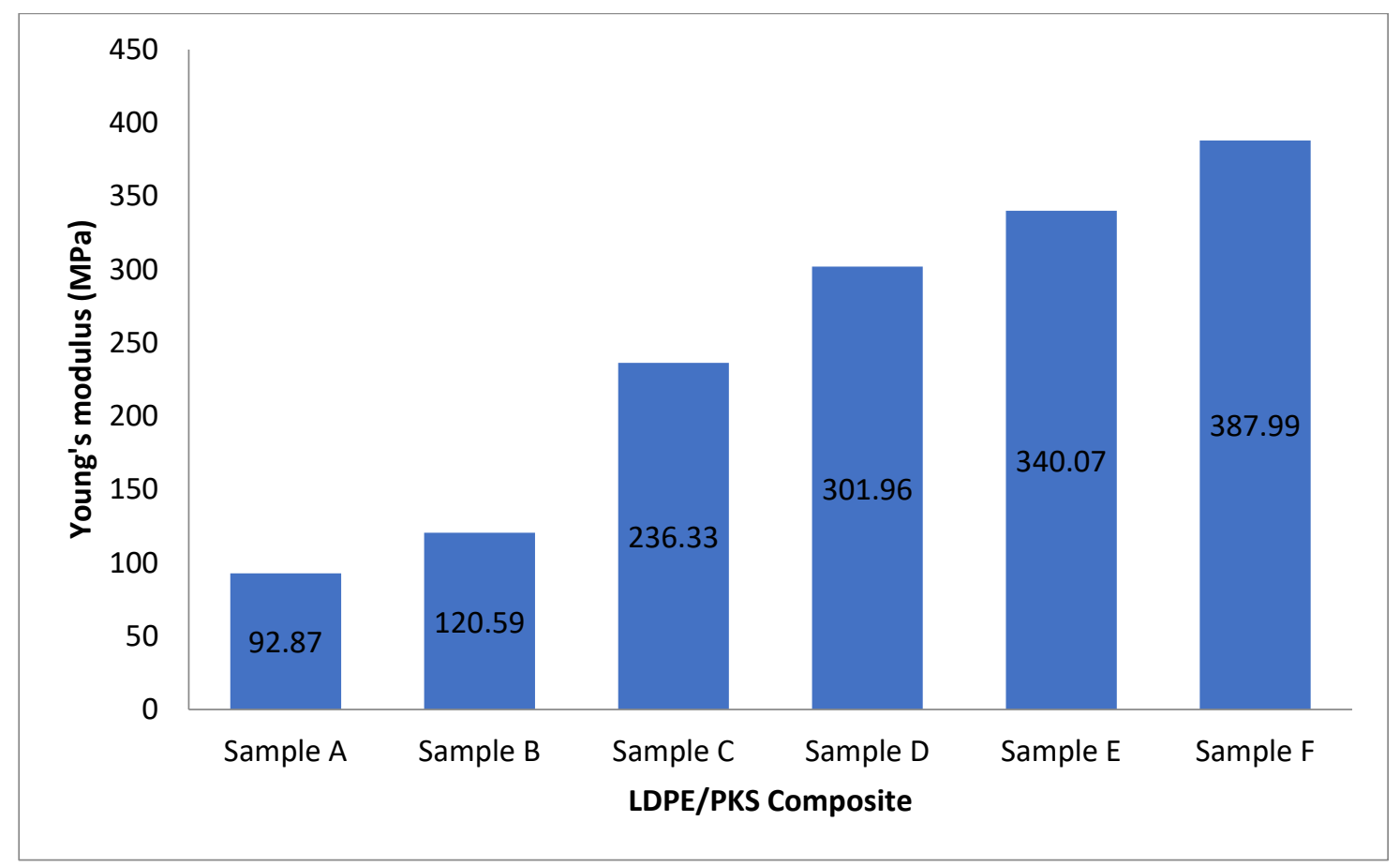

Figure 7: Young's Modulus

Figure 3 shows how palm kernel shell content affects the tensile strength of LDPE. Increasing filler reinforcement improves the tensile strength of the composite. The result showed that composite with $40 \%$ filler loading has a better tensile strength. The tensile strength increases with increasing filler loading but decreases beyond that. Lunnace et al., 2001, reported that factors affecting the reinforcement of fillers include; bonding capacity, filler dispersion and surface area.

The hardness strength also shows an increase as the filler volume ratio increases (Fig. 4) with sample $F$ possessing the best hardness property. This may be attributed to the high amount of filler loading.

The water absorption test results are shown in Fig. 5. It is clear from the figure that the composites absorb water at a steady rate. Unfilled low density polyethylene showed no sign of water absorption. This conforms to the property of LDPE with good water resistance and hydrophobic character. It was however observed that, as the amount of filler increases, the water absorption rate of the composites increases. This is attributed to the hydrophilic property of palm kernel shell.

Fig. 6 showed the percentage elongation at break (EAB) of the samples at various filler loadings. The highest result was obtained at $10 \%$ filler loading. It could be said that there is high interaction between the filler and polymer matrix leading to stiffening of chains. A decreased EAB has been explained in terms of adherence of filler to the polymer phase leading to the stiffening of polymer chains and hence resistance to stretch when the strain is applied (Salmah et al., 2012).

Young's modulus of the composite materials obtained in Fig. 7 showed that there was increase in stiffness of the materials as the filler loading increases. It can be said that modulus of filled composites depends on the amount of filler dispersion in the polymer matrix.

\section{CONCLUSION}

The essence of this research was to assess the effect of palm kernel shell filler on the mechanical properties of low density polyethylene waste. The LDPE was reinforced with palm kernel shell and the results of the research showed that young's modulus, hardness, tensile strength and water absorption increased with increasing filler loading while elongation at break decreased with increasing filler loading. Morphological studies revealed that there was a good dispersion of the filler into polymer matrix. The mechanical properties results obtained showed that PKS 
can be used as reinforcing filler for low density polyethylene waste and it indicated that the properties of the composites are greatly influenced by filler compatibility and loadings

\section{SOURCES OF FUNDING}

This research received no specific grant from any funding agency in the public, commercial, or not-for-profit sectors.

\section{CONFLICT OF INTEREST}

The author have declared that no competing interests exist.

\section{ACKNOWLEDGMENT}

None.

\section{REFERENCES}

[1] Akindapo H. and Yusuf B. Palm Oil and its Global Supply and Demand Prospect. Oil palm industry. Journal of oil research, 2017, Vol. 2:1-10.

[2] Al-kaabi k., Al-khanbashi A. and Hammami A. Date Palm Fiber as Polymeric Matrix Reinforcement. DPF/Polyester Composite Properties. Polymer compos, 2005, Vol. 26:604-613.

[3] Averous L. and Le Digabel F. B. Properties of Biocomposites based on Lignocellulosic Fillers. Carbohydrate polymers, 2006, 66:480-493.

[4] Barkar M. A., Natarajan V. D., Kalam A. and Northayatis K. Mechanical Properties of Oil Palm Fibre Reinforced Epoxy for building Short Span Bridge. Proceedings of the 13th International Conference on Engineering Materials and Structure, 2007, 103-106.

[5] Bledzki A. K. and Gassan J. Composites Reinforced with Cellulose Based Fibers. Progress in Polymer Science. 1999, 24, 221-274.

[6] Danyadi L., Moczo J. and Pukanszky B. Effect of Various Surface Modifications of Wood Flour on the Properties of PP/Wood Composites. Composites: 2009, 41: 199-206.

[7] Josmin P., Sang K. and Sabu T. Advances in Polymer Composite. Journal of polymer engineering, 2012, Vol. $11: 2$.

[8] Lunnace S., Ali R. and Nicolaise L. E. Processing Condition on Dimensions of Sisal Bers in Thermoplastic Biodegradable Composites. Journal of Applied Polymer Science, 2001, 7c (6).

[9] Pendolino K., Salmah H., Romishuani A. and Akmal H. Properties of Low Density Polyethylene/Palm Kernel Shell Composite. Effect of polyethylene co-acrylic acid. Thermoplastic composite materials, 2013, Vol. 26:215.

[10] Salmah H., Lim B. Y. and Teh P. L. Melt Rheological Behaviour and Thermal Properties of Low Density Polyethylene Palm Kernel Shell Composites. Effect of polyethylene acrylic acid. International journal of polymeric material, 2012, 61(14), 109-110.

[11] Vazquez A. M., Beltran M, and Villaricenci O. Biodegradation of Eco-toxicity of Polyethylene Films Containing Pro-oxidant Additive. Journal of polymer and the environment, 2016, Vol. 3:32-37.

[12] Wypych G. Handbook of Material Weathering, 3rd Edition, Toronto, Chem Tee publishing, 2003. 